\title{
ANÁLISE PETROGRÁFICA COMPARATIVA ENTRE XISTOS DE BAIXA PRESSÃO: REGIÕES DE ITINGA (MG), CURRAIS NOVOS (RN) E BOSSÒST (PIRINEUS CENTRAIS)
}

\author{
COMPARATIVE PETROGRAPHIC ANALYSIS BETWEEN LOW PRESSURE SHAPES: ITINGA \\ REGIONS (MG), CURRAIS NOVOS (RN) AND BOSSÒST (CENTRAL PIRINEUS)
}

\author{
Maria Vitória Ligeiro da MATTA \\ Universidade Federal de Minas Gerais. Av. Presidente Antônio Carlos, 6627, bairro Pampulha, Belo Horizonte - Minas Gerais \\ E-mail: mariavitoria.matta@gmail.com
}

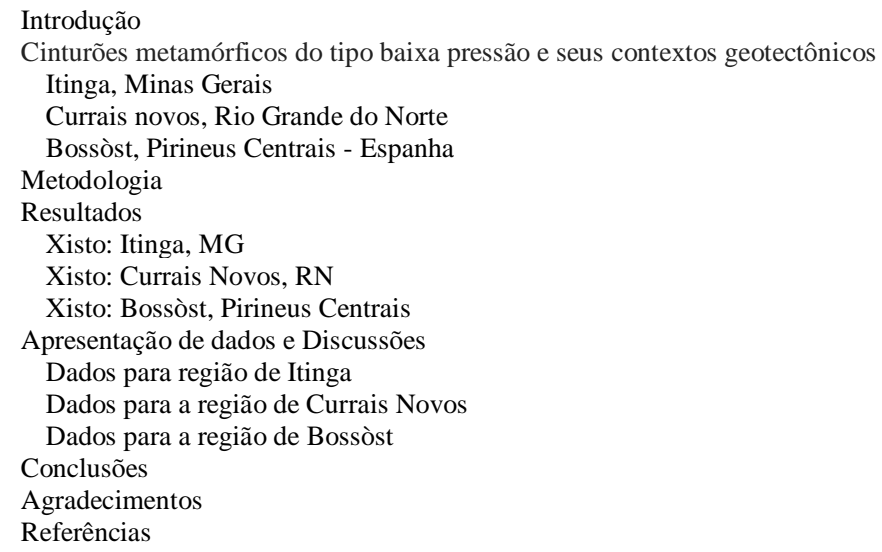

RESUMO - Cinturões metamórficos pareados são considerados uma justaposição de terrenos com fácies metamórficas apresentando diferentes intervalos de temperatura e pressão. Sua formação está relacionada com movimentos convergentes, envolvendo subducção de crosta oceânica sob outra crosta oceânica ou continental, evoluindo para situações envolvendo a colisão de placas continentais. Por conta disso, cada um desses cinturões é caracterizado por conjuntos de rochas metamórficas com paragêneses que se modificam com a progressão do metamorfismo. Cinturões formados próximos às zonas de inflexão ou convergência são identificados como do tipo alta pressão com baixas temperaturas, enquanto aqueles gerados para o interior da placa continental ou oceânica são considerados do tipo baixa pressão, mas com variações de temperatura entre as médias e altas. Visando estudos comparativos, litotipos xistosos e ricos em alumínio, provenientes das regiões de Itinga (MG), Currais Novos (RN) e Bossòst (Pirineus Centrais) foram selecionados por apresentarem histórias evolutivas semelhantes, com evidencias de polimetamorfismo e pico metamórfico sob condições de baixa pressão e em condições de fácies anfibolito. Com o auxílio de análises petrográficas foram descritas paragêneses principais compostas por andaluzitas e cordieritas, com presenças subordinadas de granadas e de estaurolitas. Para essas rochas foram analisadas correlações entre blastese e deformação, que são indicativas das transformações sofridas pelas mesmas.

Palavras-chave: Temperatura; Pressão; Petrografia; Cordierita; Andaluzita.

\begin{abstract}
Paired metamorphic belts are considered a juxtaposition of terrains with metamorphic facies presenting different temperature and pressure ranges. Its formation is related to convergent movements, involving subduction of oceanic crust under another oceanic or continental crust, evolving to situations involving the collision of continental plates. Because of this, each of these belts is characterized by set of metamorphic paragenesis that change with the progression of metamorphism. Belts formed near the inflection or convergence zones are identified as high pressure type with low temperatures, while those generated in the interior of the continental or oceanic plate are considered low pressure type but with temperature variations between averages and high. Aiming for comparative studies, shale lithotypes from the regions of Itinga (MG), Currais Novos (RN) and Bossòst (Central Pyrenees) were selected for presenting similar evolutionary histories, with evidence of polymorphism and metamorphic peaks under low pressure. With the aid of petrographic analyzes, major paragenesis composed by andaluzite and cordierite, with subordinate presence of grenades and staurolites. For these rocks correlations between blast and deformation were analyzed, which are indicative of the transformations undergone by them..
\end{abstract}

Keywords: Temperature; Pressure; Petrography; Cordierite; Andaluzite

\section{INTRODUÇÃO}

$\mathrm{O}$ entendimento à cerca dos processos responsáveis pela formação de rochas baseia-se sobretudo em observações petrográficas voltadas para a identificação de seus minerais e texturas, por esses funcionarem como registros dos processos envolvidos durante as suas formações. No caso das rochas metamórficas, e considerando apenas situações caracterizadas pela presença de cinturões com expressão regional, é consenso que seus minerais se 
encontram distribuídos nesses cinturões segundo determinadas condições de $\mathrm{P}$ e $\mathrm{T}$ (Miyashiro, 1958, 1961).

Esses cinturões têm as suas origens relacionadas a processos de subducção, com posterior evolução para ambientes colisionais, onde é maior a probabilidade de manutenção das rochas geradas sob influência de $\mathrm{T}$ e nem tanto de P. Esses cinturões, com distintas fácies metamórficas, são identificados como do tipo Baixa e Média Pressão.

Ainda que sejam enquadrados nesse tipo, cinturões de baixa pressão podem apresentar variações nas suas condições de formação, normalmente refletidas nas suas associações minerais.

Com o intuito de verificar essas variações, realizou-se estudos comparativos envolvendo três desses cinturões, cujas rochas afloram em: Itinga (MG) e Currais Novos (RN), no Brasil e na região de Bossòst, nos Pirineus Centrais, Espanha.

Essas rochas são representadas por xistos com paragêneses que refletem condições de baixa pressão, mas com temperaturas que variam de médias a altas. É possível ainda afirmar que as mesmas são típicas de zonas próximas a arcos magmáticos e caracterizam-se pela presença de minerais tais como cordierita, andaluzita e sillimanita, identificados como minerais índices e que configuram paragêneses específicas de cada fácies metamórfica (Passchier \& Trouw, 1996). Por outro lado, a presença de minerais, como a estaurolita, já identificada em dois destes cinturões, pode ser indicativa de eventuais diferenças de condições.

Embora esses cinturões já tenham sido razoavelmente estudados, em especial o da região dos Pirineus, até o momento, nenhuma pesquisa comparativa envolvendo, por exemplo, as sequências de transformações metamórficas foi desenvolvida. E uma vez que a história desses processos se encontra registrada nos arranjos texturais presentes nessas rochas, pretende-se levantar de forma detalhada as relações entre blastese e deformação para cada um dos conjuntos em estudo, buscando-se assim uma maior compreensão sobre a sequência de formação desses minerais ao longo do tempo geológico e em função de variações de T e P.

\section{CINTURÕES METAMÓRFICOS DO TIPO BAIXA PRESSÃO E SEUS CONTEXTOS GEOTECTÔNICOS}

De modo geral, rochas metamórficas encontram-se associadas a cinturões metamórficos (Miyashiro, 1958, 1961), que são considerados resultantes de processos tectônicos que levaram a uma justaposição de terrenos com condições diferentes em termos de T e de P (Miyashiro, 1961, 1973). O estudo de maior importância e considerado pioneiro na correlação de zonas de minerais índices com a variação progressiva de $\mathrm{T}$ e P foi realizado por Miyashiro (1961).

As definições de metamorfismo de baixa e de alta pressões, até hoje utilizadas, foram baseadas nas rochas presentes no clássico cinturão metamórfico emparelhado Ryoke ou baixa pressão (alta razão dT/dP) ou (Low P / High T) Sanbagawa ou alta pressão (baixa razão dT/dP) ou (High P / Low T), no Japão (Miyashiro, 1961; Ernst et al., 1970, Ernest, 1973).

No entanto, a cristalização de minerais metamórficos, assim como o aumento da granulação de minerais em função de mudanças nas condições de $\mathrm{T}$ e $\mathrm{P}$, já haviam sido observadas desde os estudos de Barrow (1893), ao analisar materiais peradevivados na região de Dalradian, na Terras Altas da Escócia (Barrow, 1893; Tilley,
1924, 1925). Barrow, 1893, interpretou sequências de minerais como resultado de uma progressão do metamorfismo, obedecendo a seguinte ordem:

- clorita $\rightarrow$ biotita $\rightarrow$ granada $\rightarrow$ estaurolita $\rightarrow$ cianita $\rightarrow$ sillimanita

Essa sequência ficou conhecida como barroviana e, em termos báricos, é indicativa de condições de média pressão (ou intermediária) e é identificada pelo par cianita-sillimanita.

Já para a região de Buchan (Miyashiro, 1973), na porção nordeste da Escócia, foi identificada uma outra sequência mineral, influenciada pelas variações de $\mathrm{T}$ sob condições de baixa pressão e identificada pela sequência:

- biotita $\rightarrow$ cordierita $\rightarrow$ andalusita $\rightarrow$ sillimanita

Anos mais tarde, com o advento da Tectônica de Placas, novas interpretações para a gênese de rochas metamórficas foram propostas, incluindo a que trata dos chamados cinturões emparelhados ou tipos báricos.

De acordo com essa proposta, os movimentos das placas tectônicas geram fontes de calor, pressões e circulação de fluidos quentes que estão diretamente relacionados com a formação de 
rochas metamórficas. Esses movimentos se associam a formação de orógenos, que envolvem zonas convergentes com a subducção de crosta oceânica sob crosta continental e cinturões colisionais.

Mais próximos às zonas de inflexão, os cinturões metamórficos encontram-se sob condições de altas pressões (baixa razão $\mathrm{dT} / \mathrm{dP}$ ) e são identificados pelo par mineral glaucofanaonfacita.

Adjacentes a estes, no lado continental da cadeia, ou mesmo em outra placa oceânica, as pressões variam de intermediárias, segundo o par mineral cianita-sillimanita, até baixas nas áreas próximas aos arcos magmáticos, com altas razões $\mathrm{dT} / \mathrm{dP}$, sendo identificados pelo par sillimanitaandaluzita.

Assim, nesse contexto, são identificados três tipos de cinturões, a saber: de alta, intermediária e de baixa pressão. Os cinturões de baixa pressão, também identificados pelo par mineral andalusitasillimanita como do tipo Abukuma (Miyashiro, 1961), New Hampshire (Turner, 1981) ou Buchan (Barrow, 1893), apresentam minerais de mais alto gradiente geotérmico, que são característicos de ambientes continentais próximo ou influenciados pelo arco magmático e deles provem as rochas que constituem os objetos de pesquisa aqui em estudo.

Considerando a associação desses cinturões com arcos magmáticos e seus fluxos térmicos, temse um ambiente propício para o metamorfismo também conhecido como térmico regional, no qual podem ser alcançadas temperaturas da ordem dos $640-700^{\circ} \mathrm{C}$, pois é nesses que se instalam corpos graníticos gerados desde as fases de subducção até as colisionais. Nesse contexto encontram-se fácies metamórficas que podem variar de xisto verde até granulítica, passando por condições adequadas para a anatexia.

A seguir são descritas as características mais importantes das três regiões pesquisadas, Itinga (MG), Currais Novos (RN) e Bossòst (Pirineus Centrais, Espanha), identificadas como polimetamórficas com eventos finais do tipo baixa pressão.

\section{Itinga, Minas Gerais}

A região de Itinga localiza-se na porção nordeste do estado de Minas Gerais, no médio Vale do Rio Jequitinhonha. Ela está inserida no Orógeno Araçuaí, que foi primeiramente descrito por Almeida (1977) devido às suas indagações em relação à faixa homônima. Anos mais tarde, autores como Brito-Neves \& Cordani (1991) e
Trompette (1994) definiram o orógeno colisional Araçuaí-Congo Ocidental, formado na Orogênese Brasiliana, contido na grande reentrância neoproterozoica-cambriana delineada pelos crátons do São Francisco e Congo (Pedrosa-Soares \& Noce, 1998; Pedrosa-Soares \& WiedemannLeonardos, 2000; Pedrosa-Soares et al., 2001, Alkmim et al., 2007).

No Médio Vale do Rio Jequitinhonha são encontradas rochas supracrustais pelíticas e cálciosilicáticas metamorfisadas que pertencem a Formação Salinas (Pedrosa-Soares et al., 1984; Costa et al., 1987, Santos et al., 2009) datada de 588 \pm 24 Ma (Pedrosa-Soares et al., 2008). Essa unidade é caracterizada por rochas metassedimentares que foram depositadas em um ambiente de leque submarino em uma plataforma relativamente estreita, associada a talude e bacia profunda, onde a deposição dos sedimentos se deu por fluxos gravitacionais e correntes de turbidez e que também haveria ação de ondas de tempestade (Pedrosa-Soares \& Wiedemann-Leonardos, 2000; Lima et al., 2002).

O Orógeno Araçuaí apresenta feições deformacionais relacionadas a dobramentos e empurrões no sentido oeste (contra o Cráton do São Francisco) e no sentido leste (contra o Cráton do Congo), e um metamorfismo regional com temperatura crescente desde a fácies xisto verde baixo até a fácies anfibolito em direção nordeste (Almeida \& Litwinski, 1984; Costa et al., 1984; Costa, 1989; Pedrosa-Soares \& WiedemannLeonardos, 2000; Silva et al., 2005). Os micaxistos das regiões de Itamarandiba, Capelinha, Virgem da Lapa, Araçuaí, Rubelita e Salinas são caracterizados como do final de fácies xisto verde até fácies anfibolito alto e sob condições de pressões intermediárias, devido à existência do par cianita-sillimanita.

Já para a região compreendida entre a cidade de Araçuaí, à oeste, e a de Itinga, à leste, as rochas metamórficas correspondem a xistos e gnaisses, que segundo Costa (1989) foram formadas sob condições de baixas pressões e temperaturas médias até altas. Essa definição se deu por conta da presença de minerais como estaurolita, andaluzita, cordierita e sillimanita nas paragêneses metamórficas.

Em trabalhos mais antigos, realizados sem detalhamentos petrográficos, o metamorfismo da área descrita foi estendido para leste e descrito como do tipo de pressão intermediária (Fontes et al., 1978; Jardim et al., 1980; Pedrosa-Soares, 1986). 
A sequência de reações metamórficas envolvendo rochas da Formação Salinas na região de Itinga foi consequência de um evento metamórfico regional e do tipo baixa pressão, relacionado com aquecimento final em função de magmatismo ácido responsável pela geração de inúmeros corpos graníticos de composição peraluminosa ou do tipo S. Esses corpos, pertencentes a suíte G4 (Monteiro, 1986; PedrosaSoares et al., 1987; Pedrosa-Soares \& WiedemannLeonardos, 2000; Silva et al., 2005), intrudiram na sequência de xistos e gnaisses encaixantes sob condições de pressão variando entre 3 e 4 kbar e com temperaturas variando entre 450 e $650{ }^{\circ} \mathrm{C}$ (Costa, 1989).

\section{Currais Novos, Rio Grande do Norte}

O município de Currais Novos localiza-se na região do Seridó no estado do Rio Grande do Norte, próximo ao limite com o estado da Paraíba. Está inserido na Província Borborema, no domínio homônimo ao estado. Estudos realizados por Brito Neves (1975) e Almeida (1977) na Província Borborema introduziram a ideia de faixa de dobramentos para a região, que serviu de respaldo junto a dados geocronológicos para a associação desses domínios tectônicos distintos ao evento do Ciclo Brasiliano, representado por extensas zonas de cisalhamento de cinemática transcorrente dúctil, com estruturas de predomínio N-NE (Brito Neves, 1983; Caby et al., 1991; Vauchez et al., 1995; Santos et al., 1984; Souza, 2007).

Na porção setentrional dessa faixa ocorrem as rochas supracrustais e cálcio-silicáticas da Formação Seridó, unidade de topo do Grupo Seridó (Ferreira \& Albuquerque, 1969; Jardim de Sá \& Salim, 1980, 1984), que é composta por micaxistos diversos muito enriquecidos em minerais aluminosos. Os litotipos da Formação Seridó são interpretados como espessos pacotes de metaturbiditos depositados em uma bacia flysch (Jardim de Sá, 1994), com idades de 620 a 580 Ma (Van Schmus et al., 2003; Nascimento et al., 2004, 2007). A variação das paragêneses que compõem os xistos da Formação Seridó abrange rochas com características de fácies xisto verde $\left(450-500{ }^{\circ} \mathrm{C}\right)$, na região de Cruzeta, até as de fácies anfibolito, nas regiões de São Vicente e Florânia (Medeiros \& Dantas, 2015)

O metamorfismo responsável pela formação dessas rochas é de caráter regional e apresenta uma sequência progressiva de minerais, envolvendo a formação de biotitas, granadas, estaurolitas, andaluzitas, cordieritas e sillimanitas. Dados geotermobarométricos indicam condições de pressões em torno de 3,5 $\pm 0,7$ kbar e temperaturas que variam entre 574 e $606{ }^{\circ} \mathrm{C}$ (Trindade et al., 2008). É importante acrescentar que a região foi intensamente afetada por inúmeras intrusões de corpos graníticos (Hollanda, 2012), em especial daqueles identificados como pertencentes a Suíte G3 (Jardim de Sá et al., 1981), que corresponderam as mais expressivas atividades ígneas e que tiveram os maiores efeitos na Formação Seridó (Trindade et al., 2008).

\section{Bossòst, Pirineus Centrais - Espanha}

Os Pirineus Centrais integram uma cordilheira extracontinental no sudoeste da Europa, na fronteira entre a França e a Espanha, separando-se, assim, a Península Ibérica do resto da Europa. Os Pirineus, de uma maneira geral, correspondem a uma cadeia montanhosa com extensão de 430 km, desde o mar Mediterrâneo (a leste) a baía de Biscaia e a cordilheira Cantábrica (a oeste). A cordilheira dos Pirineus formou-se devido ao evento orogenético colisional entre as placas Ibérica e Eurásia, durante a Orogênese Alpina no Meso-Cenozoico (Zwart, 1962), consumindo o assoalho oceânico e metamorfizando as pilhas sedimentares marinhas. Assim, a subducção da microplaca Ibérica por baixo da placa euroasiática gerou a sua integralização na forma de uma sutura com os Pirineus alocando-se em seu interior.

A porção do domínio Central dos Pirineus está localizada próximo ao domo de Bossòst, também denominado de domo Garonne. Esta é uma feição alongada no sentido E-W e datada do Carbonífero Superior (Gleizes et al., 1997) que se posiciona no centro de uma zona de cisalhamento vinculada a Northern Pyrenean Fault (Mezger, 2010). Esse plúton granítico, com núcleo composto por rochas metassedimentares fundidas, intrudiu as rochas supracrustais metamorfizadas, ricas em minerais aluminosos de origem turbidítica, datadas do Cambro-Ordoviciano (Mezger \& Passchier, 2003; Mezger, 2010). Efeitos desse evento podem ser observados nas variações composicionais das paragêneses metamórficas progressivas que se formaram em direção ao domo, em que a paragênese estaurolita, andaluzita e cordierita se transforma nas na paragênese sillimanita e cordierita ou sillimanita (Zwart, 1986; Mezger \& Passchier, 2004; Mezger, 2005).

Essas rochas passaram por um evento metamórfico que se iniciou regionalmente, relacionado com a orogenia Alpina, passando, 
posteriormente, por um intenso reaquecimento das rochas pela ascensão de plútons graníticos gerados pela orogenia Variscana, atingindo valores finais de pressão de 2-3 kbar e temperaturas de 525-600
${ }^{\circ} \mathrm{C}$ (Lamouroux et al., 1980; McCaig \& Miller, 1986; Carreras \& Cirés, 1986; Gleizes et al., 1997, 1998; Mezger \& Passchier, 2003; Mezger et al., 2004; Castiñeiras et al., 2008; Denèle et al., 2008).

\section{METODOLOGIA}

A análise comparativa à cerca das condições de formação dos xistos dos cinturões metamórficos de baixa pressão das três regiões escolhidas baseia-se em dados disponíveis em publicações e em observações petrográficas realizadas em amostras selecionadas.

A pesquisa bibliográfica foi principalmente direcionada ao entendimento das características que comprovam a existência de condições de baixa pressão para o metamorfismo nas regiões selecionadas e que levaram à formação de rochas xistosas portadoras de paragêneses de baixa pressão com a presença de minerais como a cordierita e a andaluzita.

Em uma fase preliminar, foram coletadas amostras de xistos na região de Itinga, Minas Gerais, e para as regiões de Currais Novos e Bossòst, foram selecionadas amostras que fazem parte do acervo do LABTECRochas do CPMTC/IGC-UFMG.

Após caracterização macroscópica, foram selecionadas seções que se mostraram mais adequadas para a confecção de lâminas delgadas visando às avaliações microscópicas. As descrições petrográficas microscópicas foram realizadas por meio de microscopia em luz transmitida com os objetivos de (i) identificar as assembleias minerais; (ii) identificar as paragêneses de baixa pressão; e (iii) identificar as relações entre blastese e deformação.

\section{RESULTADOS}

Em adição as informações analisadas a partir da bibliografia realizaram-se a descrição petrográfica das amostras das três regiões. Em especial, a análise das correlações de blastese versus deformação para cada mineral, esse método analítico se deu segundo proposta de Zwart (1960, 1962), que classifica as blasteses como sendo pré-, sin- ou pós- tectônicas. Segundo Passchier \& Trouw (2005), mesmo após meio século essa é uma das melhores e mais baratas opções para reconhecer e ordenar eventos.

Para o levantamento dessas relações, de início, é importante a identificação dos chamados minerais índices, que também são significativos para a caracterização das zonas de variações de intensidades do metamorfismo. No caso em questão, os minerais considerados índices foram a estaurolita, a cordierita, a andaluzita e a sillimanita, que nessa ordem indicam aumento progressivo da temperatura e do grau metamórfico.

De modo geral, as análises macroscópicas dos xistos das três localidades indicaram grandes semelhanças entre os mesmos. Ambos possuem cores acinzentadas com uma foliação bem marcada pela presença de biotitas (Figura 1A). Observa-se, ainda, a presença de cristais bem desenvolvidos (porfiroblastos) de minerais como a granada, a estaurolita, a cordierita e a andalusita
(Figuras 1D a 1G), mas em proporções diferentes para cada uma das áreas. É possível constatar que alguns dos porfiroblastos, em especial de granadas e estaurolitas, encontram-se rotacionados e que alguns de cordierita estão mais bem desenvolvidos em uma determinada direção, ultrapassando em muito o tamanho dos demais, com exceção dos de andaluzita (Figura 1B).

Em grandes corpos aflorantes verifica-se uma variação nos tamanhos dos porfiroblastos em diferentes profundidades e quando em contato com intrusões pegmatíticas, nesse último caso pode-se observar um "espelho" com cristalização de andaluzita e cordierita (Figura 1C). Notam-se ainda porções onde a variedade de $\mathrm{Al}_{2} \mathrm{SiO}_{5}$ encontrada é a sillimanita e não a andaluzita.

\section{Xistos: Itinga, MG}

Para a região de Itinga, Minas Gerais, foi observada uma associação mineral geral para os xistos formada por biotita, muscovita, granada, estaurolita, andaluzita, cordierita e sillimanita. De modo geral observa-se que a parte de granulação mais fina desses xistos é formada por quartzo, biotita e muscovita, onde o primeiro mostra contatos que variam de reto, a serrilhado. Além de apresentarem alguma variação de tamanho, grãos de quartzo podem se mostrar mais alongados, quando em contato com cristais de micas, sendo nesse observada uma foliação 
mais penetrativa. Foi observada a presença de nódulos inteiramente formados por quartzo em meio a essa parte de granulação mais fina (Figura 2A). Essa parte dos xistos constituída por cristais de quartzo mostra textura granoblástica. As biotitas, e em menor quantidade as muscovitas, marcam a foliação, e em pequenas porções podem mostrar evidências de crenulação, caracterizando a textura da rocha como lepidoblástica.

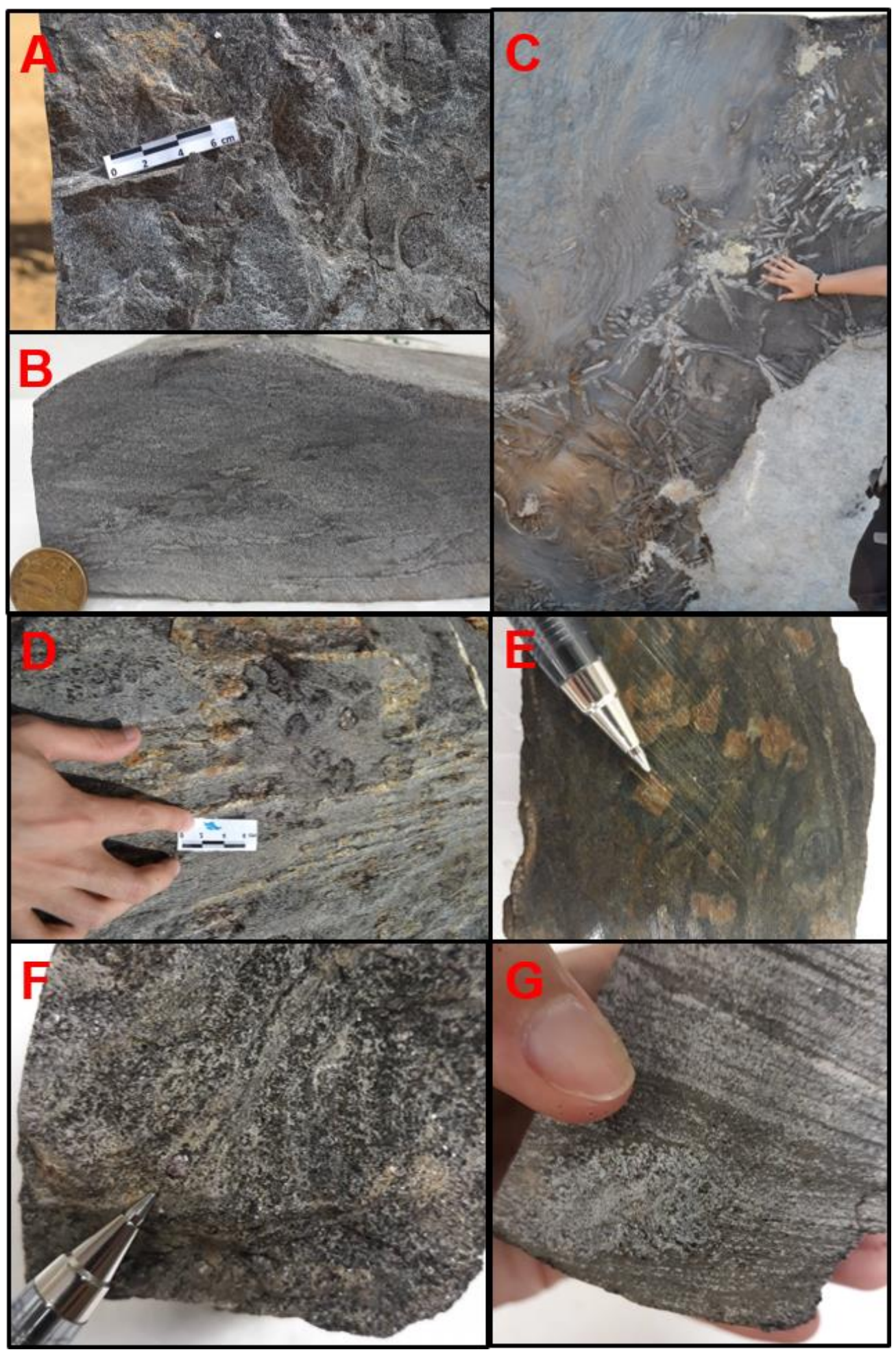

Figura 1 - Imagens ilustrativas dos estaurolita-andaluzita-cordierita-xistos. (A) Foto de afloramento em que se observa a foliação bem marcada, porém pouco penetrativa para esse xisto. Na porção inferior da imagem nota-se cristais de granada, Itinga - MG; (B) amostra com porfiroblastos de cordieritas e andaluzitas com maior desenvolvimento segundo uma determinada direção, Itinga - MG; (C) vista de contato entre o xisto e material pegmatítico, com presença de porfiroblastos de cordierita e andaluzita no xisto, Itinga - MG; (D) foto de afloramento em que se observa biotitas secundárias bordejando cristais de cordierita, Currais Novos -RN; (E) amostra de um xisto onde um cristal de andaluzita está apontado pela caneta, Bossòst - Espanha; (F) amostra de um xisto onde observa-se um porfiroblasto de granada, Bossòst - Espanha; $(\mathrm{G})$ amostra de xisto com cristal de cordierita com inclusões de biotita, Currais Novos - RN. 
Já em relação aos porfiroblastos, são observados aqueles de granadas, estaurolitas, andaluzita e de cordieritas. Os porfiroblastos de cordieritas e andaluzitas (Figuras 2B a 2D), ocorrem nas mesmas proporções. Ainda com relação aos porfiroblastos de andaluzita e de cordierita, pode-se afirmar que esses crescem envoltos ou com a foliação passando por dentro dos mesmos, indicando nesse último caso crescimentos miméticos. Nos casos em que se encontram envoltos pela foliação observam-se defecções da foliação interna em relação à externa. Em todos os casos observa-se um grande número de inclusões de quartzo e mais raramente de granada.

Já com relação aos porfiroblastos de granada, esses são bem formados. Observa-se que suas bordas podem mostrar substituições que alcançam os seus interiores por meio de microfissuras. Alguns mostram foliação interna discordantes da foliação externa (Figura 2F). Alguns desses porfiroblastos encontram-se inclusos em porfiroblastos de andaluzita (Figura 2F). As estaurolitas também ocorrem na forma de porfiroblastos nesses xistos (Figura 2G) contendo inúmeras inclusões. Costa (1987) descreve inclusões de estaurolitas em cristais de andaluzitas para a região de Itinga.

Em menor frequência, e em rochas mais a nordeste, nota-se a presença de aglomerados de sillimanita fibrosa, fibrolita (Figura 2H), e cristais de K-feldspato pertítico demonstrando outra paragênese, de temperatura mais elevada. Desse conjunto foram observadas paragêneses indicativas do aumento do grau metamórfico, onde andaluzita, por exemplo, foi substituída por sillimanita nos xistos localizados mais a nordeste.

Muscovitas, sericitas, biotitas e cloritas são observadas devido a alteração das cordieritas, andaluzitas e granadas.

\section{Xisto: Currais Novos, RN}

A associação mineral observada para é composta por biotita, granada, andaluzita e cordierita. Na literatura é citada a presença de estaurolita na região.

Com a microscopia nota-se que a matriz é composta por cristais de quartzo e biotita, onde os primeiros mostram contatos retos ou serrilhados, porém também se observa a presença de cristais com contatos interlobados. O quartzo apresenta extinção ondulante, lamelas de deformação e quando próximos a conjuntos de biotitas os cristais de quartzo adquirem formas alongadas. Às vezes observa-se alguma área com maior concentração de grãos de quartzo com granulação mais desenvolvida (Figura 3A). As biotitas e as muscovitas mostram granulação fina, ocorrendo na forma de palhetas marcando a foliação e caracterizando uma textura lepidoblástica.

São encontrados porfiroblastos de cordierita, andaluzita e granada. Os porfiroblastos de cordierita e de andaluzita mostram relações com foliação, em muito semelhantes àquelas observadas para os xistos da região de Itinga (Figuras 3B a 3D). As inclusões de quartzo e, principalmente de palhetas de biotita apresentam um arranjo mostrando alguma orientação preferencial, que pode ou não coincidir com a foliação externa. Alguns alinhamentos de inclusões mostram evidências de rotação. Observa-se ainda que em certas porções da rocha os porfiroblastos de cordierita e de andaluzita encontram-se envoltos pela foliação.

Os porfiroblastos de granada estão presentes, não são frequentes e mostram-se bem formados (Figura 3E), o que não permitiu determinar sua exata relação com a foliação da rocha. Ainda podem ser encontradas inclusões de granadas em porfiroblastos de cordierita.

Cristais ou resquícios de estaurolita não foram observados, porém em mapeamento realizado pela Companhia de Pesquisa de Recursos Minerais (CPRM), sua existência foi descrita para xistos aflorantes a oeste da região de Currais Novos (Medeiros \& Dantas, 2015). A presença da estaurolita nesses xistos constitui mais um elemento a favor de semelhanças composicionais e de metamorfismo

Foram observadas as presenças de micas e de cloritas interpretadas como secundárias e formadas devido à alteração de cordierita, andaluzita e granada (Figura 3F).

\section{Xisto: Bossòst, Pirineus Centrais}

A associação mineral predominante nesses xistos é composta por biotita, muscovita, granada, estaurolita, andaluzita e cordierita.

Nesses xistos, assim como nos anteriores, a parte de granulação mais fina é formada por cristais de quartzo, biotita e muscovita. Os grãos de quartzo mostram contatos retos até serrilhados e em alguns locais mostram-se alongados, onde a foliação é mais bem definida. Assim como nas outras duas áreas em estudo, ocorrem porções com acumulo de cristais de quartzo mais 
desenvolvidos. Dentre as micas, as palhetas de biotita ocorrem em maiores quantidades e

marcando a foliação, que pode se mostrar levemente crenulada.

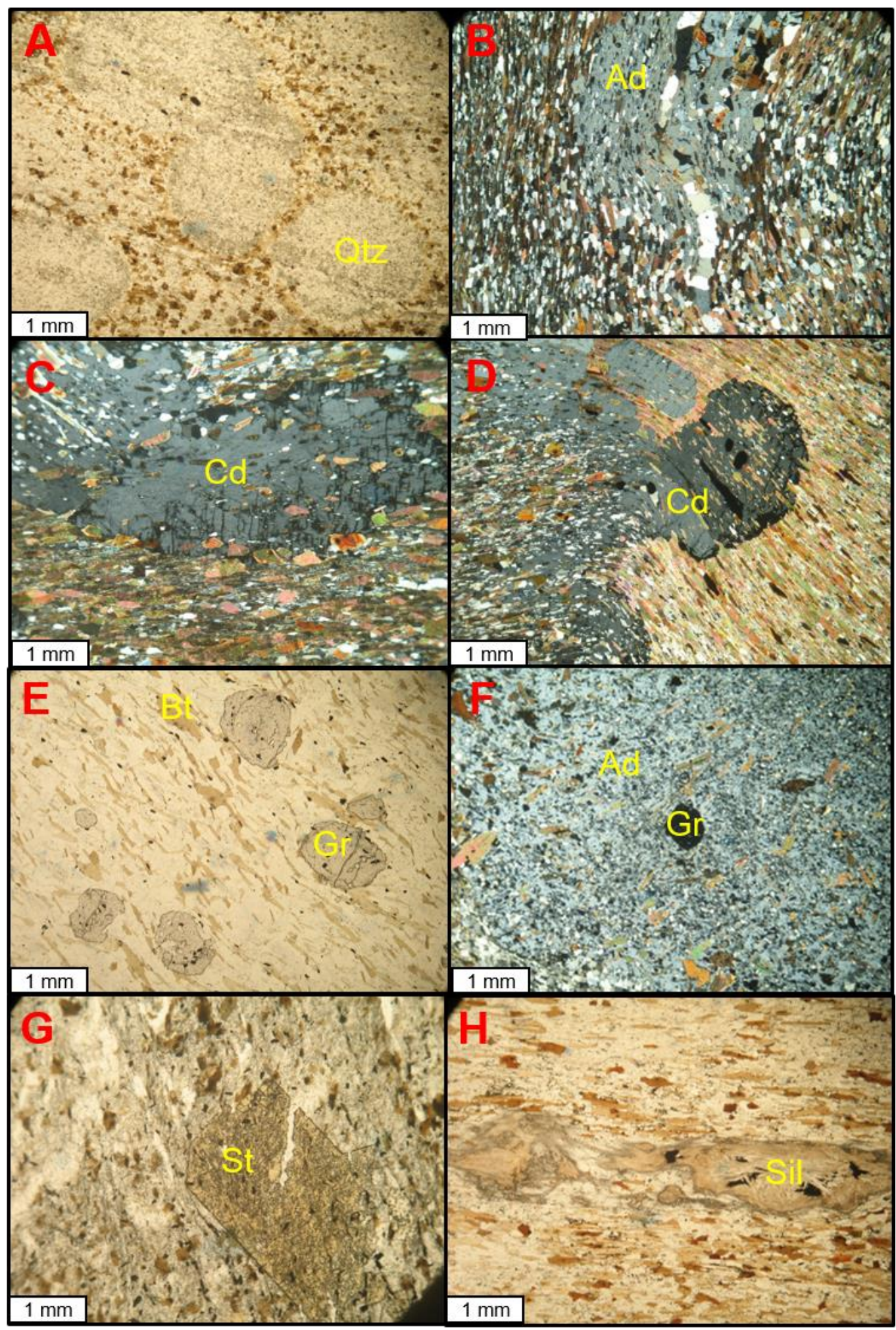

Figura 2 -Fotomicrografias dos andaluzita-cordierita-xistos. (A) Aglomerado de cristais de quartzo (Qtz) com biotita e clorita, mostrando um estrutura reliquiar da sedimentação, observa-se que o tamanho dos cristais de quartzo aumenta com a progressão do metamorfismo; (B) andaluzita (Ad) com um crescimento mimético, ainda pode-se observar a foliação e, em menores partes, crenulação marcada pela biotita; (C) porfiroblasto de cordierita (Cd) com um arranjo caótico de inclusões; (D) porfiroblasto de cordierita (Cd) com um arranjo caótico de inclusões na porção interna com microtextura helicítica; (E) cristais de granada (Gr) circundados pela foliação marcada por biotitas (Bt) e moscovitas; (F) porfiroblasto de granada $(\mathrm{Gr})$ incluso em cristal de andaluzita $(\mathrm{Ad}) ;(\mathrm{G})$ porfiroblasto de estaurolita (St) observado somente nas porções menos metamorfisadas dos xistos; $(\mathrm{H})$ porções com aglomerados de cristais aciculares de sillimanita (fibrolitas) (Sil), nessas mesmas secções ainda nota-se a presença de K-feldspato. Com exceção das fotomicrografias C, D e F, todas as demais representam situações com nicóis descruzados. Para todas foram utilizadas: ocular de 10X e objetiva de 2,5X. 


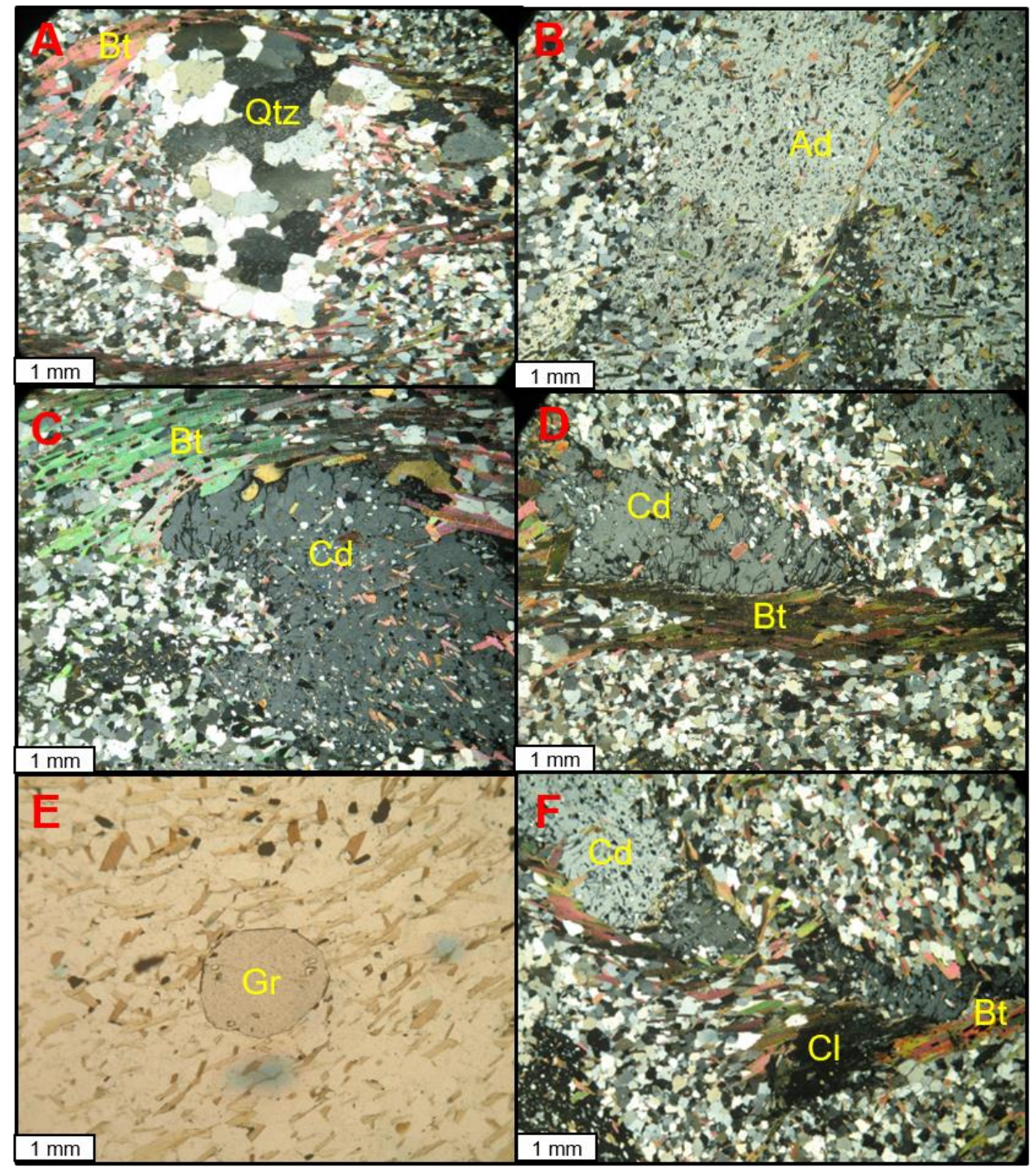

Figura 3 - Fotomicrografia dos andaluzita-cordierita-xistos (A) Porções com maior concentração de cristais de quartzo (Qtz) de maior granulação, nesses locais a foliação se torna descontínua; (B) cristal de andaluzita (Ad) poiquilítica com inclusões de cristais de quartzo e biotita. Ao entorno dos cristais nota-se que a foliação marcada pela biotita circula as andaluzitas; (C) porfiroblasto de cordierita (Cd) circundado pela foliação marcada por cristais de biotita (Bt); (D) cristal de cordierita $(\mathrm{Cd})$ circundado pela foliação; (E) porfiroblasto de granada $(\mathrm{Gr})$; (F) grãos de clorita $(\mathrm{Cl})$ gerados devido ao retrometamorfismo das cordieritas $(\mathrm{Cd})$. Com exceção da fotomicrografia $\mathrm{F}$, todas as demais representam situações com nicóis cruzados. Para todas foram utilizadas: ocular de 10X e objetiva de 2,5X.

Com relação aos porfiroblastos encontram-se os de granada, estaurolita, andaluzita e de cordierita. De fato e como nas outras áreas podem todos ser identificados como poiquiloblastos, pois contém inúmeras inclusões.

Em determinada área, a estaurolita ocorre em maior quantidade, chegando a alcançar até 4,0 $\mathrm{cm}$ de comprimento. Mostra, com frequência, aspecto esqueletal por conta das suas inúmeras inclusões de quartzo e mais raramente cristais de granada (Figuras 4A a 4C). Ao analisar as diferenças entre as posições das inclusões do centro para a borda desses poiquiloblastos e em relação à foliação externa, pode-se observar deflecção dessa foliação. Ainda em relação às estaurolitas nota-se que nas suas proximidades há uma diminuição da quantidade de biotita e um aumento das muscovitas da foliação. As cordieritas e andaluzitas podem alcançar até 3,7 $\mathrm{cm}$ de comprimento e apresentam, na maior parte das vezes, evidências de textura helicítica, mostrando crescimento mimético (Figura 4D), porém são também encontrados porfiroblastos de andaluzita envoltos pela foliação (Figura 4F).

É importante ressaltar que esses minerais se encontram em contato ou, às vezes, contendo cristais de estaurolitas (Figura 4C), o que, nesses casos, sugere reações dos últimos para a formação dos primeiros, como já mencionado para a região de Itinga, por exemplo.

Por fim, as granadas estão bem formadas, mas podem apresentar bordas com sinais de reações de substituição e inclusões de quartzo com orientações que não coincidem com a da foliação 
externa. Em relação à foliação as granadas estão em sua maioria envoltas por ela (Figura 4G) e em raras ocasiões parecem ter crescido por cima da mesma. Esses minerais ainda podem ser encontrados inclusos nos porfiroblastos de estaurolitas.

Localmente, e observando rochas de secções mais afastadas em relação ao domo granítico de Bossòst, verifica-se que a foliação é mais penetrativa, porfiroblastos são raros e cristais de andaluzita ocorrem na variedade quiastolita (Figura 4H). Nesses casos a rocha foi classificada como uma ardósia.

Moscovitas, sericitas, biotitas e cloritas ocorrem como minerais secundários da alteração dos cristais de estaurolita, cordierita e andaluzita. As biotitas secundárias possuem maiores proporções e não coincidem com a foliação da rocha e as cloritas são provenientes do retrometamorfismo das cordieritas.

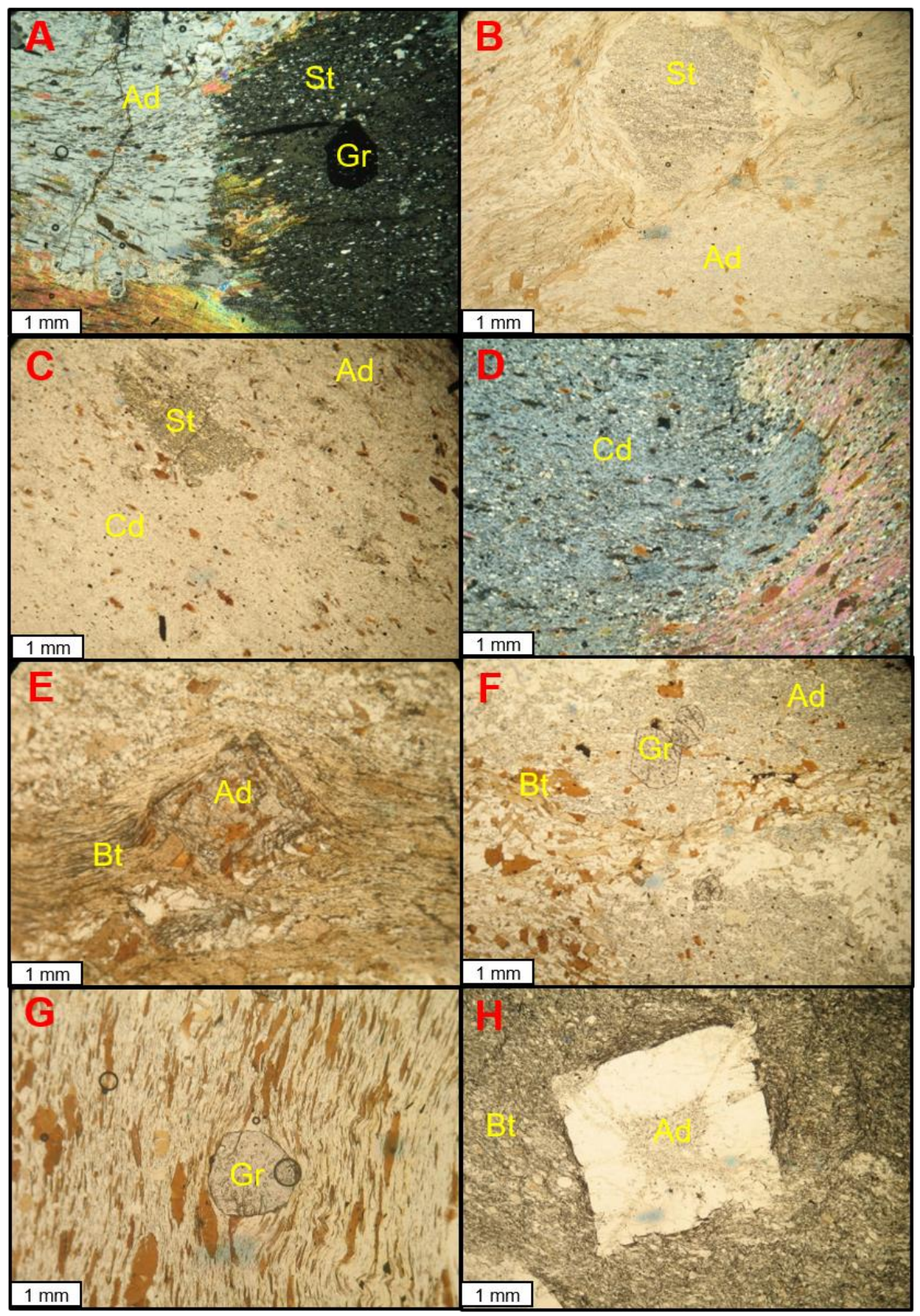

Figura 4 - Fotomicrografia dos estaurolita-andaluzita-cordierita-xistos. (A) Cristal de estaurolita (St), com inclusão de granada (Gr) e quartzo, em contato com a andaluzita (Ad), compondo uma reação metamórfica; (B) porfiroblasto de estaurolita (St) ao lado do de andaluzita (Ad), o contato é marcado por uma intensa alteração e formação de muscovita; (C) porfiroblastos de cordierita (Cd) com inclusão de estaurolita (St) demostrando uma reação metamórfica; (D) cristal de cordierita $(\mathrm{Cd})$ mostrando um crescimento mimético; (E) porfiroblasto de andaluzita (Ad) com a foliação (Bt) em seu entorno; (F) cristal de andaluzita (Ad) com inclusão de granadas $(\mathrm{Gr}) ;(\mathrm{G})$ foliação composta por biotita (Bt) circundando um porfiroblasto de granada $(\mathrm{Gr}) ;(\mathrm{H})$ cristal de andaluzita (Ad) em uma porção mais afastada e, assim, em um menor grau metamórfico. Com exceção das fotomicrografias A e D, todas as demais representam situações com nicóis descruzados. Para todas foram utilizadas: ocular de $10 \mathrm{X}$ e objetiva de $2,5 \mathrm{X}$. 


\section{APRESENTAÇÃO DE DADOS E DISCUSSÕES}

As condições do metamorfismo, assim como as fácies metamórficas correspondem a condições de $\mathrm{P}$ e $\mathrm{T}$ em que reações químicas ocorrem, com cristalização e desaparecimento de minerais índices presentes em paragêneses minerais. Essas reações podem ser deduzidas por meio de análises petrográficas, envolvendo observações de texturas, presença de bordas de reação ou de configurações de minerais indicativas do ou próximas do equilíbrio. Análises envolvendo observações das relações de contato entre porfiroblastos e as foliações, permitem, por outro lado identificar os momentos em que esses minerais, em especial os porfiroblastos se desenvolveram.

Das análises realizadas, fica entendido que os xistos das três regiões em estudo, Itinga, Currais Novos e Bossòst, passaram por histórias metamórficas e deformacionais muito parecidas e isso pode ser constatado por meio dessas observações. Em resumo, existem evidencias de um metamorfismo regional de caráter polifásico com uma paragênese final característica de baixa pressão em rochas paraderivadas.

\section{Dados para a região de Itinga}

Em relação às transformações metamórficas observadas para as rochas da região de Itinga, as Equações 1, 2 e 3 são indicadas para demonstrar a formação dos primeiros minerais metamórficos da sequência, nas faixas de mais baixa temperatura.

É importante salientar que grande parte desses minerais não resistiu ao aumento das condições de temperatura, não estando mais presentes nesses xistos.

- muscovita + clorita $=$ biotita + muscovita + quartzo $+\mathrm{H}_{2} \mathrm{O}$ - Equação 1 .

(Mielke \& Schreyer, 1969).

- clorita + muscovita + quartzo $=$ granada + biotita $+\mathrm{H}_{2} \mathrm{O}$ - Equação 2 .

(Hollister, 1966; in McAtter, 1976).

- quartzo $+\mathrm{Fe}$-clorita + magnetita $+\mathrm{H}_{2} \mathrm{O}=\mathrm{Fe}$ granada $+\mathrm{H}_{2} \mathrm{O}$ - Equação 3 .

(Hsu, 1968).

Com o aumento das condições de temperatura, e sob condições de pressões baixas a intermediárias, a estaurolita pode ter se desenvolvido como produto das reações indicadas pelas Equações 4, 5 e 6, marcando a transição da fácies xisto verde para a anfibolito.

- granada + muscovita + clorita $=$ estaurolita + biotita + quartzo $+\mathrm{H}_{2} \mathrm{O}$ - Equação 4 .

- muscovita + clorita + quartzo $=$ estaurolita + biotita + quartzo $+\mathrm{H}_{2} \mathrm{O}$ - Equação 5

(Thompson, 1978).

- clorita + muscovita $=$ estaurolita + biotita + quartzo $+\mathrm{H}_{2} \mathrm{O}$ - Equação 6 .

(Hoscherk, 1969).

Nas secções analisadas para os xistos de Itinga não foi observada somente a presença de granadas e estaurolitas (Equação 7), mas sim destas junto a andaluzitas e cordieritas (Equações 8 e 9).

- estaurolita + biotita + quartzo $=\mathrm{Fe}$-granada + muscovita $+\mathrm{H}_{2} \mathrm{O}$ - Equação 7.

- clorita + muscovita + estaurolita + quartzo $=$ andaluzita + biotita $+\mathrm{H}_{2} \mathrm{O}$ - Equação 8 .

(Labotka, 1981).

- estaurolita + muscovita + quartzo $=$ andaluzita + biotita $+\mathrm{H}_{2} \mathrm{O}$ - Equação 9 .

(Hoscherk, 1969).

Porém o desaparecimento de estaurolitas e a permanência de granadas nos xistos de mais alta temperatura, além da presença de restos de estaurolita em cristais de andaluzita, indicam que a estaurolita foi consumida com esse aumento da temperatura para formar andaluzitas ou, junto com essa para formar cordierita, conforme indicado pela Equação 10.

- estaurolita + andaluzita + clorita + quartzo $=$ cordierita $+\mathrm{H}_{2} \mathrm{O}$ - Equação 10 .

Com a progressão do metamorfismo sob condições de baixa pressão, parte dos cristais de andaluzita tanto pode ter acompanhado a formação de cordierita, quanto pode ter sido consumida para geração de cordieritas segundo reações propostas por Compton (1960), Labotka (1981), Hess (1969).

- clorita + muscovita + quartzo + ilmenita $=$ andaluzita + biotita + cordierita + ilmenita $+\mathrm{H}_{2} \mathrm{O}$ - Equação 11

- biotita + andaluzita $=$ cordierita $+\mathrm{H}_{2} \mathrm{O}$ Equação 12.

Já o final da fácies anfibolito, na área de Itinga, é identificado pelo aparecimento de sillimanita e feldspato potássico (Equação 13), mas já em ausência de outros polimorfos do $\mathrm{Al}_{2} \mathrm{SiO}_{5}$.

- muscovita + quartzo = feldspato potássico+ sillimanita $+\mathrm{H}_{2} \mathrm{O}$ - Equação 13.

(Hoffer, 1978; Best \& Weiss 1964).

Com relação aos momentos em que os 
porfiroblastos da região de Itinga, $\mathrm{MG}$, se formaram, pode-se afirmar que a maioria dos cristais de cordierita e andaluzita são posteriores (pós-tectônicos) ao desenvolvimento da foliação principal, o que é evidenciado por seus crescimentos miméticos e pela continuidade entre foliações internas e externas. Mas em algumas das rochas dessa região encontram-se evidências de que o crescimento desses minerais também ocorreu junto com o desenvolvimento da foliação (sin-tectônicos), o que é constatado pela relação entre foliações internas e externas e por feições indicando processos de rotação.

Já os cristais de granada têm a sua formação anterior (pré-tectônicos), pois a foliação envolve esses porfiroblastos. Quanto às estaurolitas, estas se formaram em momentos pré- a sin-tectônicos, devido às relações de suas linhas de inclusões.

Por todas essas observações preliminares, pode se propor que ao longo do metamorfismo progressivo, existiram duas fases principais de blastese mineral para a região de Itinga, MG. Na primeira, com o metamorfismo regional em condições de temperaturas e pressões médias, ocorreu a formação das estaurolitas e granadas, junto com a posterior rotação dos porfiroblastos (Figuras 5A, 5B). Na segunda fase, com a instalação dos corpos graníticos, ocorreu a nucleação e crescimento de andaluzitas e, posteriormente, das cordieritas (Figuras 5C, 5D). A sillimanita representa níveis de mais alta temperatura para esse metamorfismo.

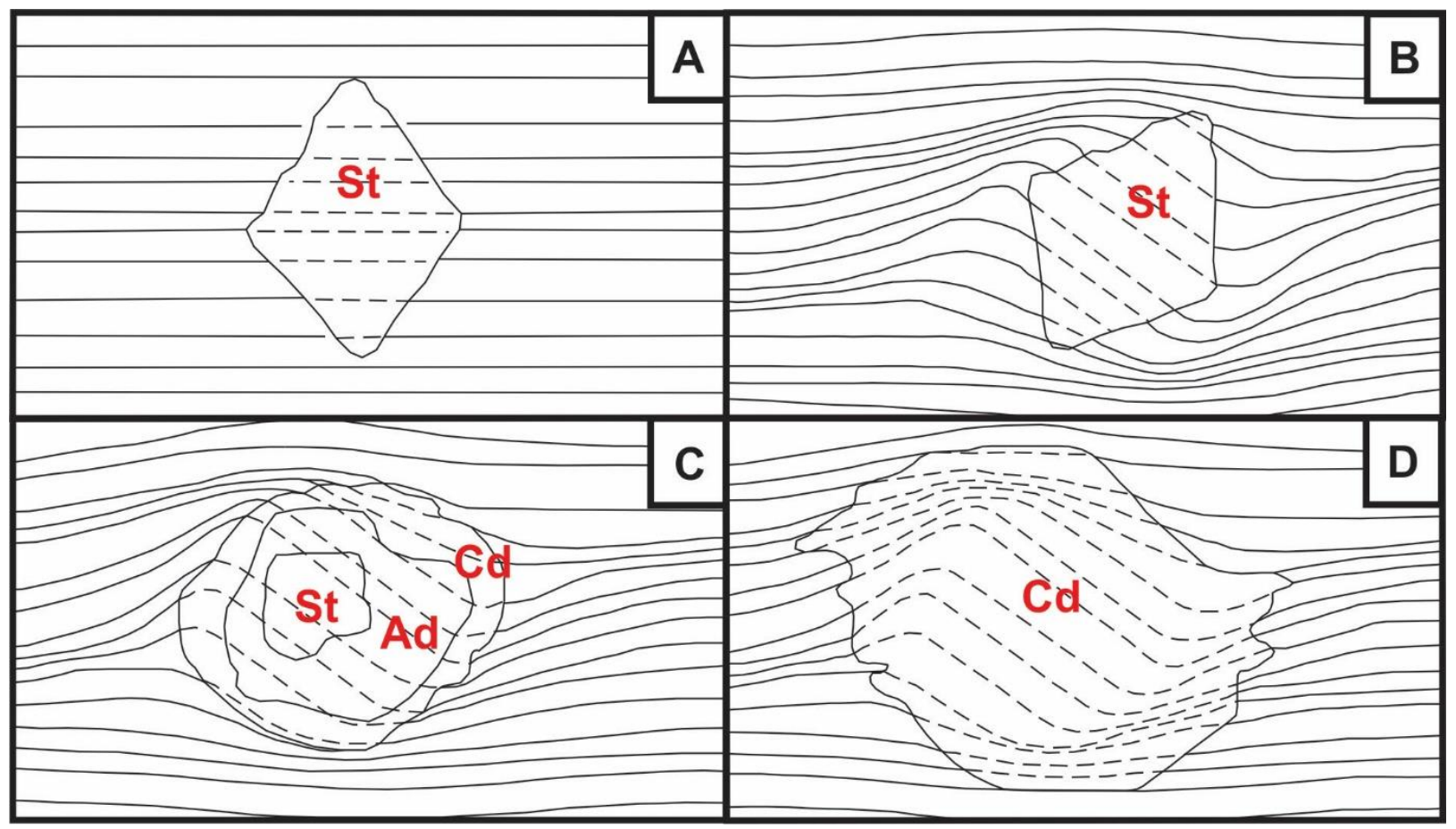

Figura 5 - Desenho esquemático para uma sequência de reações metamórficas. (A) Formação das estaurolitas prétectônicas; (B) Rotação dos cristais de estaurolitas em menores temperaturas metamórficas; (C) Transformação dos cristais de estaurolitas em andaluzitas e, posteriormente, em cordieritas com o aumento progressivo da temperatura em condições de baixa pressão; (D) Crescimento final das cordieritas por sobre a foliação. É importante ressaltar que as transformações metamórficas e a geração da foliação e/ ou crenulação ocorrem de maneira contínua. Modificado de Mezger, (2010).

\section{Dados para a região de Currais Novos}

Em relação às transformações metamórficas poucas observações puderam ser retiradas das lâminas estudadas, não tendo sido possível identificar a presença de fases minerais que pudessem ser consideradas como geradoras dos porfiroblastos de cordierita e andaluzita. Contudo, informações da literatura permitem afirmar que a série de reações para esse caso é semelhante àquelas descritas nas Equações 1 a 12. Ainda pode-se ponderar que as granadas não foram consumidas para a formação desses minerais, haja vista que não foram encontradas evidências de reações nos cristais estudados, tornado inviável uma explicação por meio da reação metamórfica da Equação 4. Foram observados pequenos cristais de feldspatos junto aos de cordieritas, presença que pode ser descrita pela Equação 15.

- $\quad$ biotita $1+$ andaluzita + quartzo = feldspato + cordierita + biotita $2+\mathrm{H}_{2} \mathrm{O}$ - Equação 15

(Currie, 1971; Best \&Weiss, 1964).

Mesmo com poucas evidências, pode-se supor que os xistos da Formação Seridó se formaram 
em condições de metamorfismo de baixa pressão, em função da presença de minerais tais como andaluzita e cordierita.

De início, um metamorfismo do tipo regional foi responsável pela formação de granada e/ ou a formação do mineral precursor das andaluzitas e cordieritas, possivelmente a estaurolita (Figuras $6 \mathrm{~A}, 5 \mathrm{~B})$. Seguindo essa fase, houve um aumento da temperatura em função da instalação dos granitos G3, ao ponto de iniciar a formação das andaluzitas e cordieritas (Figura 6C). Por fim, e sob condições de deformação, cristais de cordierita continuaram seu crescimento (Figura 6D).

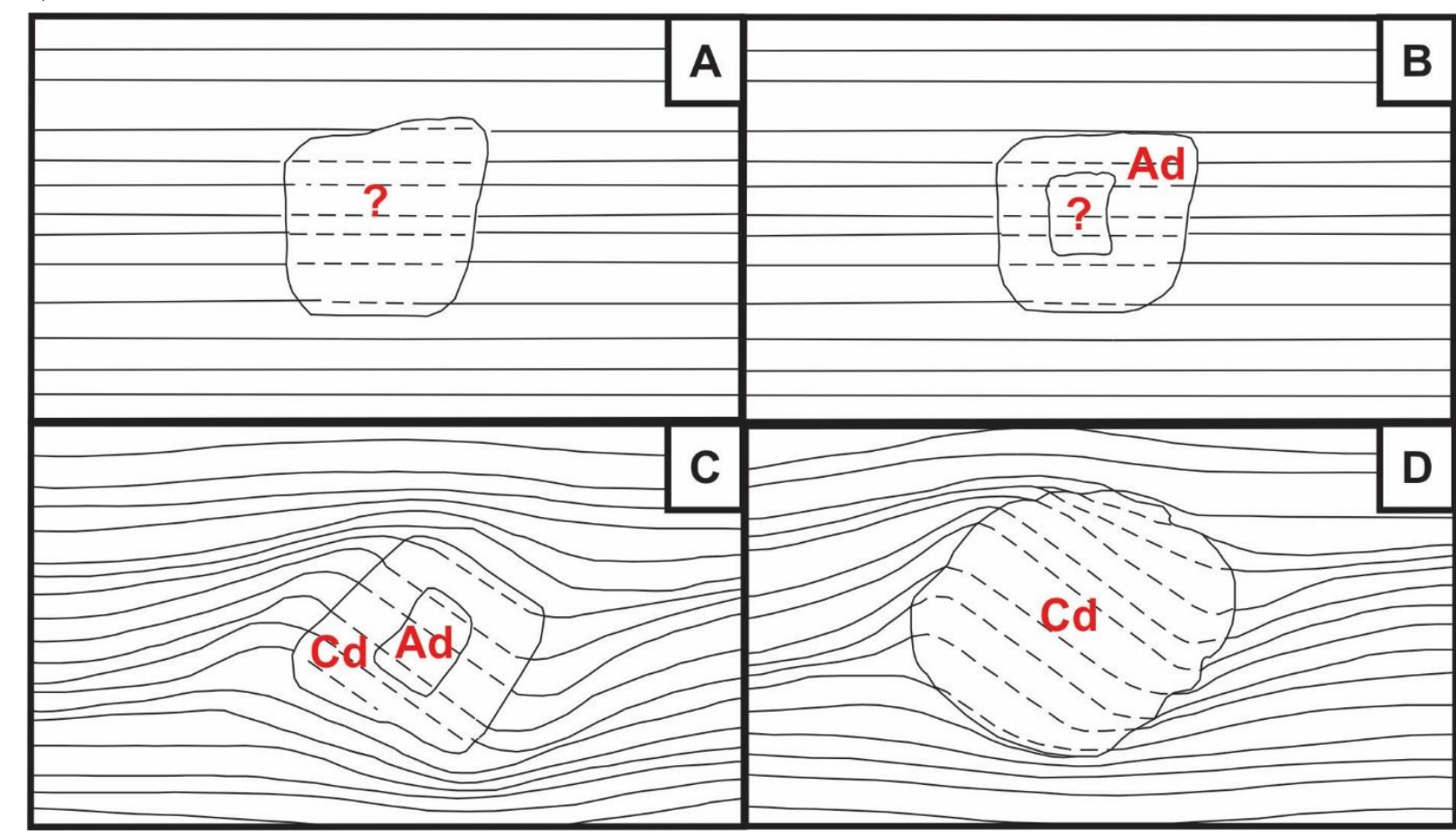

Com relação às relações entre blastese e deformação para os xistos da Formação Seridó (Currais Novos, RN), se constata que os porfiroblastos de cordierita e de andaluzita se formaram anteriormente à finalização do desenvolvimento da foliação principal e por isso são sin- a tardi tectônicos, nem sempre mostrando arranjos de inclusões em que a foliação externa coincide com a interna.

Já cristais de granada são, em sua maioria, anteriores ao desenvolvimento da foliação principal (pré-tectônico). Podem também ser observados ocorrendo inclusos nos pórfiroblastos de cordierita.

Figura 6 - Desenho esquemático para uma sequência de blastese sin-tectônica, proposta para a região de Currais Novos. De (A) até (D) tem-se a uma provável transformação de andaluzita em cordierita.

\section{Dados para a região de Bossòst}

Com relação às mudanças metamórficas para essa região, observa-se que a estaurolita, granada e biotita foram em parte consumidas para a formação das andaluzitas e cordieritas. Em parte, porque existem pontos onde estaurolita encontrase estável junto a cristais de andaluzitas e de cordieritas. As Equações de 1 a 12, descritas para as outras duas regiões podem ser utilizadas para explicar a presença dos minerais observados.

Mas também foram observadas inclusões de estaurolita em cordieritas e andaluzitas (Equação 16), porém sempre com a presença de muita alteração.

- estaurolita + muscovita + quartzo $=$ andaluzita/ sillimanita + biotita + Zn-estaurolita + granada $+\mathrm{H}_{2} \mathrm{O}$ - Equação 16.
(Guidotti, 1969, 1974).

Ainda se verifica que parte dos cristais de granada e biotita possuem bordas corroídas, mostrando que esses foram em parte alterados. Já as andaluzitas recém-formadas foram subsequentemente consumidas, junto com a biotita, para formar cordierita, e são preservadas como grãos reliquiares nesse mineral (Equação 12).

Aqui, uma primeira fase, possivelmente relacionada ao metamorfismo da Orogênese Alpina, foi responsável pela nucleação das granadas. Posteriormente, as estaurolitas, cresceram sobre a antiga foliação e com a ascensão dos granitos do domo de Bossòst (Orogênese Variscana), ocorreu à nucleação da andaluzita e da cordierita, em parte com o 
consumo da estaurolita (Figuras 6 A a D).

Já em relação ao tema blastese versus deformação, nota-se para os xistos que ocorrem nas proximidades do domo de Bossòst, Pirineus Centrais, que as linhas de inclusões de quartzo presentes nas estaurolitas mostram uma deflecção com relação à foliação externa, com crescimento da estaurolita sendo pré- a sintectônico em relação à foliação principal. As granadas, anteriores (pré-tectônica) a essa foliação, estão envoltas.

Já as cordieritas e andaluzitas, assim como em Itinga, cresceram, principalmente, de forma mimética (pós-tectônica). Ainda assim, são encontrados cristais de andaluzita que começaram a se formar anteriormente a foliação (pré- e sin-tectônica), estando circundados por ela.

Considerando a presença de minerais como cordierita e andaluzita, é possível caracterizar o metamorfismo da área como do tipo baixa pressão, com muitas semelhanças com aqueles das outras regiões estudadas.

Finalizando e com relação às três regiões, pode-se resumir as informações analisadas para as transformações metamórficas em seis pontos:

(i) a cianita não é um mineral presente nas paragêneses estudadas o que confirma serem de baixa pressão, onde a andaluzita representa condições de temperaturas mais baixas e a sillimanita mais altas;

(ii) a cordierita é um mineral presente com andaluzita e com sillimanita;

(iii) a granada é pouco abundante, e em algumas rochas aparece coexistindo com a cordierita;

(iv) a estaurolita, quando não está presente, foi considerada consumida para a formação de outros minerais, como a andaluzita;

$(v)$ a associação da cordierita com a sillimanita é indicativo de aumento da temperatura;

(vi) inclusões de granadas nas cordieritas podem ser indicativos de descompressão;

Em adição as discussões acima, pode-se aventar a hipótese de que os protólitos dessas rochas foram depositados em porções semelhantes de uma sequência turbidítica, com pequenas variações nos teores de pelitos entre si.

\section{CONCLUSÕES}

Em todas as três regiões em estudo, ocorrem litotipos metamórficos paraderivados com ambientes de formação semelhantes, o que resultou na geração de rochas sob condições de baixa pressão Abukuma (Miyashiro, 1961). Este tipo de série metamórfica apresenta minerais de alto gradiente geotérmico, alta razão $T / P$, normalmente com andaluzita e cordierita fazendo parte de suas paragêneses. Existem evidências de que em todas as três regiões um metamorfismo regional de caráter polifásico foi responsável pela geração dessas paragêneses com características de baixa pressão. Variações entre as localidades baseiam-se nas condições de $\mathrm{T}$ e $\mathrm{P}$, nas diferenças entre as relações de blastese versus deformação e os eventos metamórficos e deformacionais. Além disso, a observação entre uma paragênese composta por estaurolitas e granadas em comparação com porções afetadas por temperaturas mais altas, com uma paragênese caracterizada por andaluzitas, cordieritas e sillimanitas, demonstra que os primeiros minerais foram utilizados para formar os mais recentes.

\section{AGRADECIMENTOS}

A autora agradece ao LABTECRochas do CPMTC/IGC-UFMG por disponibilizar parte do acervo para pesquisa. Ao geólogo Vinícius H. Sena e as empresas K2 e Rocha Verde por agirem de prontidão em fornecer material para a pesquisa.

\section{REFERÊNCIAS}

ALKMIM, F.F.; PEDROSA-SOARES, A.C., NOCE, C.M; CRUZ, S.C.P. Sobre a Evolução Tectônica do Orógeno Araçuaí-Congo Ocidental. Geonomos, v. 15, n. 1, p. 25 - 43, 2007.

ALMEIDA, F.F.M. \& LITWINSKI, N. Província Mantiqueira (setor setentrional). In: ALMEIDA, F.F. \& HASUI, Y. (coord.) O PréCambriano do Brasil. Ed. Blücher, São Paulo, 282 p., 1984.

ALMEIDA, F.F.M. O Cráton do São Francisco. Revista Brasileira de Geociências, v. 7, p. 349-364, 1977.

BARROW, G. On an intrusion of muscovite-biotite-gneiss in the southeastern Highlands of Scotland, and its accompanying metamorphism. Quarterly Journal of the Geological Society of London, v. 49, p. 330-358, 1893.
BEST, M.G. \& WEISS, L.E. Mineralogical Relations in some pelitic Hornfelse from the Southern Sierra Nevada, California. American Mineralogist, v. 49, p. 1240-1266, 1964.

BRITO NEVES, B.B. O mapa geológico do Nordeste oriental do Brasil, escala 1: 1.000.000. São Paulo, SP. 1983. Tese (Livre-Docência), Instituto de Geociências, Universidade de São Paulo.

BRITO NEVES, B.B. Regionalização geotectônica do Précambriano nordestino. São Paulo, 1975. 198 p. Tese (Doutorado), Instituto de Geociências, Universidade de São Paulo.

CABY, R.; SIAL, A.N.; ARTHAUND, M.H.; VAUCHEZ, A. 
Crustal evolution and Brasiliano orogeny in Northeast Brazil. In: DALLMEYER, R. D. \& LÉCORCHÉ, J. P. (eds). The West African orogens and circum-atlantic correlatives. SpringerVerlag, p. 373-397, 1991.

CARRERAS, J. \& CIRÉS, J. The geological significance of the western termination of the Mérens fault at Port Vell, (Central Pyrenees). Tectonophysics, v. 129, 99-114, 1986.

CASTIÑEIRAS, P.; NAVIDAD, M.; LIESA, M.; CARRERAS, J.; CASAS, J.M. U-Pb zircon ages (SHRIMP) for Cadomian and early Ordovician magmatism in the Eastern Pyrenees: new insights into the pre-Varisca evolution of the northern Gondwana margin. Tectonophysics, v.461, p. 228-239, 2008.

COMPTON, R.R. Contact metamorphism in Santa Rosa Range, Nevada. Bull. Geol. Soc. Am., v. 71, p. 1383-1416, 1960

COSTA, A.G. Petrologie und geochemische Untersuchungen des gneis-migmatit-gebietes von Itinga, Jequitinhonha-Tal, Nordoestlisches Minas Gerais, Brasilien, 1987. 288 p. Tese (Doutorado), TU-Clausthal University of Technology.

COSTA, A.G. Evolução petrológica para uma sequência de rochas metamórficas regionais do tipo baixa pressão, Itinga, NE-MG Revista Brasileira de Geociências, v. 19, p. 440-448, 1989.

COSTA, A.G.; CORREIA NEVES, J.M.; MÜLLER, G. Feições polimetamórficas da região de Itinga, Minas Gerais. In: CONGRESSO BRASILEIRO DE GEOLOGIA, 33, Rio de Janeiro, 1984. Anais... Rio de Janeiro: Sociedade Brasileira de Geologia, 1984, v.8, p. 3166-3180.

CURRIE, K.L. The reaction -3 cordierite $=2$ garnet +4 sillimanite + 5 quartz as a geological thermometer in the Opinicon Lake Region, Ontario. Contrib. Mineral. Petrol., v. 33, p. 215-226, 1971.

DENÈLE, Y.; OLIVIER, P.; GLEIZES, G. Progressive deformation of a zone of magma transfer in a transpressional regime: the Variscan Mérens shear zone (Pyrenees, France). Journal of Structural Geology, v. 30, p. 1138-1149, 2008

ERNST, W.G. Interpretative Synthesis of Metamorphism in the Alps. GSA Bulletin, v. 84, n. 6, p. 2053-2078, 1973.

ERNST, W.G.; SEKI, Y.; ONUKI, H.; GILBERT, M.C. Comparative Study of Low-Grade Metamorphism in the California Coast Ranges and the Outer Metamorphic Belt of Japan. In: DONNAY, L. D. H. \& WKRNER, N. Comparative Study of Low-Grade Metamorphism in the California Coast Ranges and the Outer Metamorphic Belt of Japan Geological Society of America, 1 v., Inc. Memoir 124, 1970.

FERREIRA, J.A.M. \& ALBUQUERQUE, J.P.T. Sinopse da geologia da Folha Seridó. SUDENE, Departamento de Recursos Naturais, Divisão de Geologia, série Geologia Regional, v. 18, 47 p. 1969.

FONTES, C.Q.; FERRARI, P.G.; PEREIRA, A.A.C.; NETTO, C.; PEREIRA, F.S.; LIMA, L.O.J.; COSTA, M.R.A.; BALTAZAR, O.F.; SILVA, S.L.; VIEIRA, V.S.; RAMALHO, R. Projeto Jequitinhonha. Escala 1: 250.000. Belo Horizonte, DNPM/CPRM, Relatório Final, 368p. 1978.

GLEIZES, G.; LEBLANC, D.; BOUCHEZ, J. L. Variscan granites of the Pyrenees revisited: their role as syntectonic markers of the orogen. Terra Nova, v. 9, p. 38-41, 1997.

GLEIZES, G.; LEBLANC, D.; BOUCHEZ, J.L. The main phase of the Hercynian orogeny in the Pyrenees is a dextral transpression. In: HOLDSWORTH, R.E.; STRACHAN, R.A.; DEWEY, J.F (Eds). Continental Transpressional and Transtensional Tectonics. Geological Society Special Publication, v. 135, p. 267-273, 1998.

GUIDOTTI, C.V. A comment on chemical study of minerals from the Moine Schists of the Ardnamurchan Area, Argyllshire, Scotland by B. C. Butler, and its implications for the phengite problem. J. Petrology, v. 10, p. 164-170, 1969.

GUIDOTTI, C.V. Transition from staurolite to sillimaanite zone, Rangeley Quadrangle, Maine. Geol. Soc. Am. Bull., v. 85, p. 475-490, 1974.

HESS, P.C. The metamorphic paragenesis of cordierite in pelitic rocks. Contrib. Mineral Petrol., v. 24, p. 191-207, 1969.
HOFFER, E. Melting reactions in aluminous metapelites: stability limits of biotite + sillimanite + quartz in the presence of albite. Neues Jahrb. Miner., Monat., v. 9, p. 396-407, 1978. HOLLANDA, M.H.B.M. Geocronologia de eventos magmáticos e mineralizações associadas no Precambriano da Faixa Seridó, Província Borborema, São Paulo. 2012. Tese (Livre-Docência), Instituto de Geociências-Universidade de São Paulo.

HOSCHERK, G. The stability of staurolite and chloritoid and their significance in metamorphism of pelitic rocks. Contrib. Mineral. Petrol., v. 27, p. 208-232, 1969.

HSU, L.C. Selected phase relationships in the system Al-Mn-Fe-SiO; a model for garnet equilibra. J. Petrology, v. 9 p. 40-83, 1968.

JARDIM DE SÁ, E.F. \& SALIM, J. Reavaliação dos conceitos estratigráficos na região do Seridó (RN-PB). Miner. Metal., v. 80, n. 421, p. 16-28, 1980.

JARDIM DE SÁ, E.F. A Faixa Seridó (Província Borborema, NE do Brasil) e o seu significado geodinâmico na cadeia Brasiliana/Pan Africana. Brasília, 1994. 803p. Tese (Doutorado), Instituto de Geociências-Universidade de Brasília.

JARDIM DE SÁ, E.F.; LEGRAND, J.M.; MCREATH, I. Estratigrafia de rochas granitóides na região do Seridó (RNPB), com base em critérios estruturais. Rev. Bras. Geoc., v. 11, n. 1, p. 50-57, 1981.

JARDIM, F.G.; ARAÚJO, A.G.; LIMA, J.O.A.; MELLO, M.P.; MARTINS JR., P.P. Projeto estudos integrados do Vale do Jequitinhonha - estudos geológicos e recursos minerais. Relatório Final (1:250.000). Fund. Centro Téc. De Minas Gerais (Cetec), Belo Horizonte. 1980.

LABOTKA, T.C. Petrology of na andalusite-type regional metamorphic terrane, Panamint mountains, California. J. Petrology, v. 22, p. 261-296, 1981.

LAMOUROUX, C.; SOULA, J.C.; DÉRAMOND, J.; DEBAT, P. Shear zones in the granodioritic massifs of the Central Pyrenees and the behaviour of these massifs during the Alpine orogenesis. Journal of Structural Geology, v. 2, p. 49-53, 1980.

LIMA, S.A.A.; MARTINS-NETO, M.A.; PEDROSA-SOARES, A.C.; CORDANI, U.G.; NUTMAN, A. A Formação Salinas na área-tipo, NE de Minas Gerais: Uma proposta de revisão da estratigrafia da Faixa Araçuaí com base em evidências sedimentares, metamórficas e idades U-Pb SHRIMP. Revista Brasileira de Geociências, v. 32, p. 491-500, 2002.

MARSHAK, S.; ALKMIM, F.F.; WHITTINGTON, A.; PEDROSA-SOARES, A.C. Extensional collapse in the Neoproterozoic Araçuaí orogen, eastern Brazil: A setting for reactivation of asymmetric crenulation cleavage. Journal Structural Geology, v. 28, 129-147, 2006.

MCATTER, C. Formation of garnets in a rock from Mallaig. Contributions to Mineralogy and Petrology, v. 55, p. 293301, 1976

MCCAIG, A.M. \& MILLER, J.A. 40Ar-39Ar age of mylonites along the Merens fault, central Pyrenees. Tectonophysics, v. 129, p. 149-172, 1986.

MEDEIROS, V.C. \& DANTAS, E.P. Geologia e Recursos Minerais da Folha Currais Novos (escala 1:100.000), estados do Rio Grande do Norte e Paraíba. Programa Geologia do Brasil, CPRM, Recife, Pernambuco, 2015.

MEZGER, J.E. Comparison of the western Aston-Hospitalet and the Bossòst domes: Evidence for polymetamorphism and its implications for the Variscan tectonic evolution of the Axial Zone of the Pyrenees. Journal of the Virtual Explorer, v. 19, Paper 6, 2005.

MEZGER, J.E. Mimicking syntectonic growth: cordierite overgrowth of earlier rotated staurolite porphyroblasts, strain caps and deflected foliation. Journal of Structural Geology, v. 32, 703-708, 2010.

MEZGER, J.E. \& PASSCHIER, C.W. Comment on "Identification of an underfilled foreland basin system in the Upper Devonian of the Central Pyrenees: implications for the 
Hercynian orogeny". International Journal of Earth Sciences, v. 93, p. 467-470, 2004.

MEZGER, J.E. \& PASSCHIER, C.W. Polymetamorphism and ductile deformation of staurolite-cordierite schist of the Bossòst dome: indication for Variscan extension in the Axial Zone of the central Pyrenees. Geological Magazine, v. 140, p. 595-612, 2003.

MEZGER, J.E.; PASSCHIER, C.W.; RÉGNIER, J.L. Metastable staurolite-cordierite assemblage of the Bossòst dome: Late Variscan decompression and polyphase metamorphism in the Axial Zone of the central Pyrenees. Comptes Rendus Geoscience, v. 336, p.827-837, 2004.

MIELKE, H. \& SCHREYER, W. Mineralparagenesen in Metasedimenten des Fichtel Gebirges. Geologica Bavarica, v. 60, p. 29-44, 1969.

MIYASHIRO, A. Regional metamorphism of the GoscisyoTakamki district in the central Abukuma Plateau. Tokyo Univ. Fac. Scientific Jornal, v. 11, p. 219-272, 1958.

MIYASHIRO, A. Evolution of Metamorphic Belts. Journal of Petrology, v. 2, Issue 3, p. 277-311, 1961.

MIYASHIRO, A. Metamorphism and metamorphic belts George Allen \& Unwin, London, 492p. 1973.

MONTEIRO, R.L.B.P. As Mineralizações de Tungstênio no Médio Vale do Jequitinhonha, NE de Minas Gerais, Brasil. Brasília, 1986, 171 p. Dissertação (Mestrado), Instituto de Geociências - Universidade de Brasília.

NASCIMENTO, R.S.C.; SIAL A.N.; PIMENTEL, M.M. C and Sr isotope systematics applied to Neoproterozoic marbles of the Seridó Belt, Northeastern Brazil. Chemical Geology, v. 237, p. 191-210, 2007.

NASCIMENTO, R.S.C.; SIAL, A.N.; PIMENTEL, M.M Chemostratigraphy of medium-grade marbles of the late Neoproterozoic Seridó Group, Seridó Fold Belt, Northeastern Brazil. Gondwana Research, v. 7, n. 3, p.731-744, 2004.

PASSCHIER, C.W. \& TROUW, R.A.J. Microtectonics. Springer-Verlag, Berlim, 366 p., 1996.

PASSCHIER, C.W; TROUW, R.A.J. Microtectonics. 2.ed. Publisher: Springer-Verlag Berlin Heidelberg, 2005.

PEDROSA-SOARES, A.C. \& NOCE, C.M. Where is the suture zone of the Neoproterozoic Araçuaí-West-Congo orogen? In: CONFERENCE ON BASEMENT TECTONICS, 14, 1998, Ouro Preto. Extended Abstracts...Ouro Preto: Sociedade Brasileira de Geologia, 1998, v. 1, p. 35-37.

PEDROSA-SOARES, A.C. \& WIEDEMANN-LEONARDOS, C.M. Evolution of the Araçuaí Belt and its connection to the Ribeira Belt, Eastern Brazil. In: CORDANI, U.; MILANI, E THOMAZ-FILHO, A.; CAMPOS, D. A. (eds), Tectonic Evolution of South America. São Paulo, Sociedade Brasileira de Geologia, p. 265-285. 2000.

PEDROSA-SOARES, A.C., MONTEIRO, R., CORREIA-NEVES, J.M., LEONARDOS, O.H.; FUZIKAWA, K. Metasomatic evolution of granites, northeast Minas Gerais, Brazil. Revista Brasileira de Geociências, v. 17, p. 512-518, 1987.

PEDROSA-SOARES, A.C.; ALKMIM, F.F.; TACK, L.; NOCE, C.M.; BABINSKI, M.; SILVA, L.C.; MARTINS-NETO, M.A. Similarities and differences between the Brazilian and African counterparts of the Neoproterozoic Araçuaí-West-Congo orogen. Geological Society, London, Special Publications 294, 2008.

PEDROSA-SOARES, A.C.; LEONARDOS, O.H.; CORREIANEVES, J.M. Aspectos metamórficos de sequências supracrustais da Faixa Araçuaí em Minas Gerais. In: CONGRESSO BRASILEIRO DE GEOLOGIA, 33, Rio de Janeiro. 1984. Anais...Rio de Janeiro: Sociedade Brasileira de Geologia, 1984, v. 7, p. 3056-3068.
PEDROSA-SOARES, A.C.; NOCE, C.M.; WIEDEMANN, C.M.; PINTO, C.P. The Araçuaí-West Congo orogen in Brazil: An overview of a confined orogen formed during Gondwanland assembly. Precambrian Research, v. 110, p. 307-323, 2001.

SANTOS, E.J. \& BRITO NEVES, B.B. Província Borborema. In: ALMEIDA, F.F.M.; HASUI, Y. (eds). O Pré-Cambriano do Brasil. Edgard Blucher, p. 123-186, 1984.

SANTOS, R.F.; ALKMIM, F.F.; PEDROSA-SOARES, A.C. A Formação Salinas, Orógeno Araçuaí, MG: História deformacional e significado tectônico. Revista Brasileira de Geociências, v. 39, n. 1, p. 81 - 100, 2009.

SILVA, L.C.; MCNAUGHTON, N.J.; ARMSTRONG, R.; HARTMANN, L.; FLETCHER, I. The Neoproterozoic Mantiqueira Province and its African connections. Precambrian Research, v. 136, p. 203-240, 2005.

SOUZA, L.C.; LEGRAND, J.M.; VERKAEREN, J. Metamorfismo térmico nos micaxistos Seridó em torno do batólito granítico de Acarí (RN), nordeste do Brasil: química mineral de ilmenitas e turmalinas. Estudos Geológicos, v. 17, n. 2, p. 65-79, 2007.

THOMPSON, A.B. Archean regional metamorphism in the slave Structural Province. A new perspective on some old rocks. Geological Survey of Canada Paper, v. 78, n. 10, p. 85-102, 1978.

TILLEY, C.E. A Preliminary Survey of Metamorphic Zones in the Southern Highlands of Scotland. Quarterly Journal of the Geological Society of London, v. 81, p. 100-112, 1925.

TILLEY, C.E. Contact-Metamorphism in the Cowrie Area of the Perthshire Highlands. Quarterly Journal of the Geological Society of London, v. 80, p. 22-71, 1924.

TRINDADE, I.R.; MARTINS SÁ, J.; MACEDO, M.H.F. Comportamento de elementos químicos em rochas mineralizadas em ouro na Faixa Seridó, Província Borborema. Revista Brasileira de Geociências, v. 38, n. 2, p. 303-318, 2008.

TROMPETTE, R. Geology of Western Gondwana (2000-500 Ma). Pan-African-Brasiliano aggregation of South America and Africa. Rotterdam, A.A. Balkema, 350 p. 1994.

TURNER, F.J. Metamorphic petrology. McGraw-Hill Book Company, 694 p., 1981.

VAN SCHMUS, W.R.; BRITO NEVES, B.B.; WILLIAMS, I.S.; HACKSPACHER, P.C.; FETTER, A.H.; DANTAS, E.L.; BABINSKI, M. The Seridó Group of NE Brazil, a late Neoproterozoic pre-to syn-collisional basin in West Gondwana: insigthts from SHRIMP U-Pb detrital zircon ages and $\mathrm{Sm}-\mathrm{Nd}$ crustal residence (TDM) ages. Precambrian Research, v. 127 , p. 287-327, 2003.

VAUCHEZ, A.; NEVES, S.; CABY, R.; CORSINI, M.; EGYDIO-SILVA, M.; AETHAUD, M.; AMARO, V.E. The Borborema Shear Zone System, NE Brazil. Journal of South American Earth Sciences, v. 8, p. 247-266, 1995

ZWART, H.J. On the determination of polymetamorphic mineral associations, and its application to the Bosost area (Central Pyrenees). Geologische Rundschau, v. 52, p. 38-65, 1962.

ZWART, H.J. The chronological succession of folding and metamorphism in the Central Pyrenees. Geologische Rundschau, v. 50, p. 203-218, 1960.

ZWART, H.J. The Variscan orogeny of the Pyrenees. Tectonophysics, v. 129, p. 9-27, 1986.

Submetido em 16 de abril de 2019 Aceito em 10 de outubro de 2019 